When a prospective employee is applying for a job, such as air pilot or engine driver, in which his sudden incapacity can hazard the lives of others, there is of course no ethical objection to the doctor's recommending his rejection if he is found to have a condition making him liable to such incapacity. But many people applying for jobs where this risk to others does not arise are nevertheless compelled to have a medical examination. And although they have all the right qualifications and are accepted "subject to medical examination" they may later be informed that because they have "failed" the medical they cannot after all have the job. I have come across many such rejects during my medical career. In the Guardian of 23 August 1978 appeared a news item under the heading "“'Healthy' man who failed medical loses job." The man concerned had obtained a job as a porter and bench hand but the company doctor found he had hypertension and commented, "I am sure he is fit for work, but we are not so much concerned about his present health as his future health." If this kind of medical rejection can be justified by one doctor working for one corporation, it can equally be justified by other doctors working for other corporations. In consequence, unfortunates with, say, hypertension, diabetes, heart murmurs, and albuminuria may be unable to get any employment.

I have suggested ${ }^{1}$ that those doctors who advise rejection on medical grounds need the following modified version of the Hippocratic Oath: "The regimen I adopt shall be for the benefit of my patients according to my ability and judgment, and not for their hurt or for any wrong, unless I am examining them on behalf of an employer, when the welfare of the patient shall count for nothing, and the interests of the employer shall be my sole concern." Such doctors would do well to consider how they would feel if they were at the receiving end. Suppose that a senior registrar, after years of fruitless application for consultant appointments, is finally made a consultant "subject to medical examination." $\mathrm{He}$ is later informed that because his blood pressure is too high he cannot become a consultant after all. Would his rage and despair be lessened by the kindly assurance of the chairman of the appointments committee that he will be able to stay on as a supernumerary senior registrar?

JoHN W TodD

Farnham, Surrey GU9 8DR

' Todd, J W, Lancet, 1965, 1, 797.

\section{A patient's charter}

SIR,-I wish to comment on the stimulating paper by the late Dr B B Zeitlyn (14 July, p 103).

Despite the merits of many staff, and allowing for the unattractive presentation of some of the people with whom they deal, it seems clear that some patients sadly are downgraded in their contact with the NHS. This hazard extends ac zoss all strata of staff, being related to temperamental and social factors rather than to status. An example of the former might be a personal need to seek relationships with the dependent and a liability to react angrily if superiority is challenged, while in the latter group is the erroneous "them and us" ethos to which Dr Zeitlyn referred.
My own experiences as a patient or patient's relative have generally been very favourable but I am uneasily aware that this may not be typical. Sensitivity training and opportunities effectively to ventilate various stresses should help toward better awareness of psychodynamics, and indeed most of us may benefit from recognising the more destructive as well as the more constructive aspects of our personalities.

Patients and relatives could perhaps often become more complete partners in the therapeutic efforts (rather than appearing as objects to be manipulated), and this does not deny them the security of professional decisiveness when this is justified. An increase in the already almost intolerable pressures on some NHS staff is not implied, and with an easing of relationships actual improvement in this respect could follow.

K S JONES

Cowbridge, South Glam CF7 7QR

\section{Royal Commission report}

SIR,-In attacking the independent contractor status of general practitioners, the Royal Commission has done a very great disservice to the NHS. In health as in any other form of personal service, the true interests of the individual can never be protected and fostered by professional workers employed directly by the State.

While there is some hope (but no guarantee) that the present government will refuse to implement these disastrous proposals, in the long term there is considerable danger that some power-hungry future administration will seek to implement them. This prospect must weigh heavily in the minds of young doctors coming into general practice, and will influence their motivation in many subtle ways, none of which will be to the advantage of their patients.

It is important that the BMA declares its total opposition to the general introduction of a salaried service for GPs, and pursues this policy with skill, persistence, and determination.

Cyril Hart

Peterborough, Cambs PE7 3JL

SIR,-The report of the Royal Commission ${ }^{1}$ has, I believe, neglected to clarify the role of community physicians, and because of this discussion is complicated by whether the community physician is regarded as a specialist doctor or an administrator. This highlights the dichotomy between the roles of specialist adviser in epidemiology and that of medical administrator.

Medical administrators work as officers to health authorities and this role is neither that of an independent adviser nor that of a representative of medical staff." However, the function of the specialist adviser in epidemiology is more that of an independent consultant and it is in this capacity that the community physician may, in the interests of the health of the population, need to put forward proposals which are not necessarily those of the health authority.

The recent report by the Unit for the Study of Health-Policy, ${ }^{3}$ addressing itself to the low morale and lack of recruitment within the specialty, recognises this problem when it proposes the creation of local health promotion teams. The report realistically accepts that in order to function effectively the members of these teams should have independence and political support.

The report of the Royal Commission explicitly states that the specialty must be supported in the next few years if it is to survive. However, its recommendations for the provision of adequate supporting staff, guidance on consensus management, and the formation of a central Institute of Health Services Research will probably help only to a limited extent. If, as the report states, the specialty has a future and "the present decline should not be allowed to continue," then something more radical is needed.

The Duncan report ${ }^{4}$ confirmed the need for two types of career appointment within community medicine. However, it is probably only by a much firmer commitment to the independent specialist consultant role that the potential of community medicine may be realised.

\section{A A WARD}

Crowborough, E Sussex

'Royal Commission on the National Health Service, Report, Cmnd 7615. London, HMSO, 1979. Cang, S, et al, Doctors and the NHS. Brunel Institute of Organisation and Social Studies, 1978.

Unit for the Study of Health Policy, Rethinking Community Medicine: Towards a Renaissance in Health Policy, 1979

4 Joint Working Party, The State of Community Medicine. London, British Medical Association and Faculty of Community Medicine, 1979

SIR,-I am dismayed at the Royal Commission report that care by some doctors is mediocre in general practice. The commission blames inadequate training and a set of national standards, yet no one mentions work load.

We often see patients at five-minute intervals. Why ? Because we need so many on our lists to make practice financially viable. I calculate that if I gave every patient the 20 minutes or so they require I would be working 24 hours continuously per day.

No, neither this report nor the audit suggested is valid considering the condition of general practice today. You cannot criticise or audit a system whose structure is basically unsound. Until GPs' lists are cut by giving them fair remuneration per patient this report is not valid. Audit work, by all means, but at least give us time to think.

Timperley, Cheshire WA156QQ

B Caplan

\section{A medical union in the United States}

SIR,-I read with interest Dr J D J Havard's article "A medical union in the United States" (2 June, p 1500).

The problems of malpractice insurance, which have stayed at crisis levels for several years, are the result of the legal system prevailing in the United States. Lawyers take most civil liability cases on a contingency basis, getting nothing if they lose but up to $50 \%$ plus expenses if they win. This has resulted in intense antagonism between the medical and legal professions, although only a relatively few lawyers engage in malpractice work. (However, it is ethical for a trial lawyer to pay part of his fee to the referring attorney, although fee splitting by the medical profession is both unethical and illegal.)

Unfortunately the membership of most state 